\title{
Kernos
}

Revue internationale et pluridisciplinaire de religion grecque antique

$23 \mid 2010$

Varia

\section{Marie-Françoise BASLEZ, Les persécutions dans l'Antiquité. Victimes, héros, martyrs}

\section{Aurian Delli Pizzi}

Édition électronique
URL : http://journals.openedition.org/kernos/1635

DOI : 10.4000/kernos. 1635

ISSN : 2034-7871

\section{Éditeur}

Centre international d'étude de la religion grecque antique

\section{Édition imprimée}

Date de publication : 1 janvier 2010

Pagination : 386-389

ISSN : 0776-3824

\section{Référence électronique}

Aurian Delli Pizzi, «Marie-Françoise baslez, Les persécutions dans l'Antiquité. Victimes, héros, martyrs », Kernos [En ligne], 23 | 2010, mis en ligne le 15 septembre 2011, consulté le 21 septembre 2020. URL : http://journals.openedition.org/kernos/1635; DOI : https://doi.org/10.4000/kernos.1635

Ce document a été généré automatiquement le 21 septembre 2020.

Kernos 


\title{
Marie-Françoise BASLEZ, Les persécutions dans l'Antiquité. Victimes, héros, martyrs
}

\author{
Aurian Delli Pizzi
}

\section{RÉFÉRENCE}

Marie-Françoise BASLEZ, Les persécutions dans l'Antiquité. Victimes, héros, martyrs, Paris, Fayard, 2007. 1 vol. 15 × 23,5 cm. 417 p. ISBN : 978-2 -213-63212-4.

1 La question de la persécution dans l'Antiquité fait partie des dossiers délicats à traiter, tant il est rare de recueillir, sur un même fait, le point de vue du persécuteur et celui du persécuté. Dans son ouvrage, l'A. entend étudier les persécutions antiques en adoptant le point de vue le plus objectif possible. Pour ce faire, elle examine les sources littéraires dans des contextes bien précis, pour lesquels on dispose d'une documentation suffisamment fournie: Socrate à Athènes, Polycarpe et Pionios à Smyrne, les cités d'Afrique lors de la Grande Persécution, etc. C'est d'ailleurs sans doute pour éviter tout parti pris et un point de vue trop restrictif qu'elle ne donne pas, dans son introduction, de définition stricte du concept de persécution, mais en cite plusieurs caractéristiques: "sublimation de la mort» et "souffrance au nom d'une religion, d'une foi ou d'une cause » (p.5) pour le martyre, " prise de conscience d'une menace » (p.6) pour la persécution, etc. Contrairement à de nombreuses études qui se sont limitées à des dossiers précis, l'A. situe son sujet dans un cadre chronologique très large, à savoir depuis les procès de philosophes pour impiété vers $440 \mathrm{av}$. J.-C. jusqu'au concile de Nicée en 325 ap. J.-C.

2 L'étude de ce vaste sujet se fait en trois parties thématiques : « Les stéréotypes de la persécution », «L'invention du martyre » et « Religion, droit et liberté : les chrétiens et l'Empire ». Il est principalement question des religions grecque, romaine, juive et chrétienne et des interactions entre elles et avec les autorités politiques, mais le propos 
envisage également la place de courants religieux moins centraux (cultes orientaux, manichéisme, etc.) ${ }^{1}$.

3 L'analyse du cas de Socrate et des autres philosophes athéniens (Aristote, Théophraste, etc.) met en exergue plusieurs éléments relatifs à la place du penseur dans la cité antique et à l'influence que ces philosophes ont exercée sur les courants de pensée ultérieurs. La condamnation de Socrate, particulièrement, a été largement réinterprétée comme exemple parfait de "mort témoignage » : aux yeux des chrétiens, il est mort en essayant de faire connaître le dieu unique à ses concitoyens. Si l'on analyse les enjeux des poursuites contre les philosophes grecs, on constate qu'ils sont persécutés pas tant pour leurs idées que pour leur remise en question d'un consensus civique, du fondement même de la cité. Comme le souligne l'A., la condamnation de Socrate illustre le caractère relatif du crime religieux dans la cité antique, dont la gravité dépend de la place occupée par le coupable au sein de la cité. D’autre part, ces cas montrent les limites de la tolérance de la cité antique: bien qu'elle prône la $\pi \alpha \rho p \eta \sigma i ́ \alpha$, elle n'en demeure pas moins très méfiante à l'égard d'individus particuliers qui en font un usage contestataire. Ce caractère provocateur et la volonté d'aller au devant de la mort au lieu de l'éviter sont des éléments que l'on retrouve dans de nombreux cas ultérieurs de persécution. Par exemple, aux $\mathrm{II}^{\mathrm{e}}$ et $\mathrm{III}^{\mathrm{e}}$ siècles, du côté chrétien, la mort volontaire est perçue comme une voie d'accès au salut, notamment parce qu'elle permet d'imiter le Christ, même si elle reste une exception.

4 L'A. s'intéresse également aux groupes d'individus (écoles philosophiques, cultes étrangers, etc.), qu'elle réunit sous les catégories de «sectes » et « associations », et au regard que la législation antique porte sur ceux-ci. L'usage qui est fait du terme « association » est tout à fait fondé : il rappelle que les cultes étrangers ne constituent pas, aux yeux des Grecs, une catégorie bien définie, mais relèvent des associations au sens large. Sur ce point, il ressort que le droit antique a redouté principalement le caractère potentiellement factieux de certaines associations. Cette crainte a poussé celles-ci à se montrer aussi transparentes que possible. L'affaire de la profanation des Mystères et de la mutilation des hermès à Athènes, et le scandale des Bacchanales à Rome constituent des exemples symptomatiques, mais exceptionnels, de recherche systématique de l'impiété par peur d'une entreprise de déstabilisation de l'État. Mis à part ces deux cas, il est rare que le délit religieux soit sanctionné autrement qu’à la suite d'un flagrant délit. La persécution des philosophes est également due au particularisme de certaines écoles philosophiques. Dans ce cas, la solution trouvée par les philosophes est de faire de leur école un sanctuaire, c'est-à-dire, en d'autres termes, d'exploiter la religion comme support pour rester dans la légalité. D'autre part, s'il est vrai que les cultes étrangers à Athènes sont d'abord restés cantonnés au port du Pirée, on ne peut parler d'exclusion, dans la mesure où les seuls litiges que l'on puisse trouver par rapport à ces cultes relèvent de questions plus techniques qu'idéologiques (finances, concurrence entre divinités, etc.).

5 En définitive, l'analyse de l'A. montre qu'Athènes favorise l'implantation de cultes étrangers sur son territoire, se montrant plus «tolérante " que ne le laisse entendre Flavius Josèphe. Il est néanmoins indéniable que, s'agissant d'appréhender un culte étranger, la société antique au sens large - pas la Grèce uniquement - fait généralement preuve d'« amalgame », c'est-à-dire qu'elle transpose sur quelque chose d'inconnu des éléments qui lui sont familiers. 
6 Le rapport aux cultes étrangers diffère dans les royaumes hellénistiques, où la sacralisation croissante du souverain, qui atteint son apogée sous le roi séleucide Antiochos IV, provoque un refus de la part des Juifs de participer au culte dynastique. C'est à cette époque que sévit la "crise maccabéenne", qui fait l'objet d'un long développement dans l'ouvrage. Il faut remarquer cependant que ces persécutions n'étaient pas destinées à éradiquer le peuple juif, mais à le pousser à prendre part au culte dynastique.

7 Les conclusions sont intéressantes. D'un point de vue général, on ne peut pas dire que, dans l'Antiquité, les persécutions sont dirigées contre une idéologie ou une doctrine : ce sont des personnes précises qui sont visées, dans un contexte donné. Bien plus, dans le contexte de la persécution du christianisme par les autorités romaines, le persécuté est rarement sommé d'abjurer sa doctrine et la seule exigence à laquelle il est soumis est de respecter son devoir civique. D'autre part, il faut relativiser la théorie du bouc émissaire : une persécution, même à grande échelle (par exemple, la mise à mort des chrétiens par Néron), ne consiste pas nécessairement à rejeter la faute sur une communauté en raison, par exemple, d'une catastrophe naturelle. D'autre part, bien que la littérature de persécution (Oracle du potier, Livres des Maccabées, etc.), évidemment subjective, présente le persécuteur comme le «méchant » par excellence, il faut replacer l'acte de persécution dans un contexte plus large. Par exemple, bien qu'il soit présenté comme persécuteur des chrétiens, l'empereur romain Dèce inscrit son action dans une politique de restauration tout à fait positive de l'empire.

8 "L'histoire du martyre, c'est une autre histoire. En d'autres termes, un persécuté est-il toujours un martyr?» (p. 9). L'A. envisage le martyre comme un cas particulier de la persécution, qui relève d'une représentation subjective et appartient à l'histoire des représentations. En termes de représentation, l'A. s'intéresse notamment au regard porté sur la mort. Sur ce point, les Grecs et les Juifs diffèrent fondamentalement. La «belle mort » des Grecs consiste à mourir au combat et ne peut avoir lieu que lorsque le héros a pu démontrer sa valeur. Pour les Juifs, au contraire, il s'agit avant tout de mourir pour la Loi, prématurément si nécessaire. De plus, le point de vue juif accorde une place importance aux détails sanglants des supplices, alors que, pour les Grecs, le cadavre doit rester intact et beau. Quant au point de vue chrétien, force est de constater que, même s'il faut imiter le Christ, la recherche de la mort reste une exception et sera progressivement remplacée par l'ascèse. D'ailleurs, le suicide tel qu'il est pratiqué à Rome ne sera jamais bien vu des chrétiens.

9 La figure du martyr chrétien s'avère fortement ambivalente. Certes, elle est indispensable à la communauté : « Comme le héros homérique, le martyr est la colonne qui soutient sa communauté, qui la consolide et qui la maintient cohérente et unie, malgré des tendances centrifuges » (p. 260). L'A. montre d'ailleurs comment des figures singulières du christianisme parviennent à s'imposer comme des références et comment un culte leur est parfois rendu, ce qui n'est pas sans rappeler le culte voué aux héros grecs. Toutefois, les martyrs sont des figures d'exception et, en ce sens, ils sont tout autant susceptibles d'accentuer les discordes qui secouent le christianisme à ses débuts.

10 Il faut s'attendre à ce que tous les lecteurs ne soient pas convaincus de l'homogénéité de cet ouvrage et du bien-fondé d'étudier les persécutions dans un cadre chronologique si large. Dans une étude d'une telle ampleur, qui met en scène des époques et des acteurs si différents, ce sont certainement des chapitres pris isolément plutôt que 
l'ensemble de l'ouvrage qui emporteront l'adhésion, en fonction des intérêts de chacun. Plus objectivement, on regrettera l'absence d'index, non que l'usage de l'index soit maintenant tellement répandu qu'un ouvrage dépourvu de cet outil soit automatiquement défectueux, mais pour un exposé si riche, qui évoque tant de personnages à plusieurs reprises et développe certains concepts dans différents chapitres (comme le concept d'«amalgame» par exemple), cela fait cruellement défaut. Pour pallier en partie ce manque, on dispose de repères chronologiques au début de l'ouvrage. Quoi qu'il en soit, l'analyse apportée par l'A. sur les différents cas de persécution et sur la figure du martyr est à la fois innovante et réussie, et contribue à remettre en question des idées reçues (par exemple, la conception selon laquelle les persécutions seraient issues de « chocs de civilisations»).

\section{NOTES}

1. Que l'on me permette de me centrer principalement, dans le cadre de ce compte rendu, sur les questions relatives à la religion grecque et à ses rapports aux autres religions.

\section{AUTEURS}

\section{AURIAN DELLI PIZZI}

Université de Liège 